\title{
Lesiones osteolíticas de la calota
}

\author{
Osteolytic lesions of skull cap
}

\section{CASE REPORT}

We report the case of a Caucasian 71-year-old female with schizophrenia, who presented to the emergency room with traumatic brain injury after falling. At the beginning, general surgery assessed the patient, and a skull X-ray was performed. It revealed multiple lytic injuries in the skull cap (figure 1) and with this finding, she was admitted in the Internal Medicine ward.

On physical examination she presented skin and mucous paleness, as well as a $5 \times 3 \mathrm{~cm}$ nodule on the upper exterior quadrant of the right breast, irregular, with poorly defined edges and a palpable ipsilateral axillary adenopathy. Under these findings, a thorax-abdomen-pelvic computerized tomography was requested. It revealed diffuse involvement of the whole skeleton and confirmed the presence of a nodule. Under breast tumour with bone metastasis suspicion, patient was conducted for a breast eco-guided biopsy, confirming the presence of invasive carcinoma "no special type", starting hormonotherapy with letrozole.

Bone is one of the most common metastasis areas. ${ }^{1}$ Skeleton osteolytic injuries often are evidenced in multiple myeloma and other solid tumours such as breast and lung. ${ }^{2}$ Differential diagnosis of lytic bone lesions can include primary malign bone injuries, bone metastasis or even benign bones injuries. ${ }^{1}$ Considering this, evaluation of a patient with these lesions becomes a challenge. Its clinical case intends to highlight the importance of physical examination, the key in the diagnostic process. Most bone metastasis are asymptomatic; however, it becomes a sign of advanced disease. ${ }^{3}$

\section{REFERENCES}

1. Coleman RE. Clinical features of metastatic bone disease and risk of skeletal morbidity. Clin Cancer Res. 2006;12(20 Pt 2):6243s-6249s.

2. Pockett RD, Castellano D, McEwan P, Oglesby A, Barber BL, Chung K. The hospital burden of disease associated with bone metastases and skeletal-related events in patients with breast cancer, lung cancer, or prostate cancer in Spain. Eur J Cancer Care (Engl). 2010;19(6):755-760.

3. Hamaoka T, Madewell JE, Podoloff DA, Hortobagyi GN, Ueno NT. Bone imaging in metastatic breast cancer. J Clin Oncol. 2004;22(14):2942-2953.

Palabras clave: lesiones osteolíticas, cáncer de mama, metástasis óseas Keywords: osteolytic lesions, breast tumor, bone metastasis

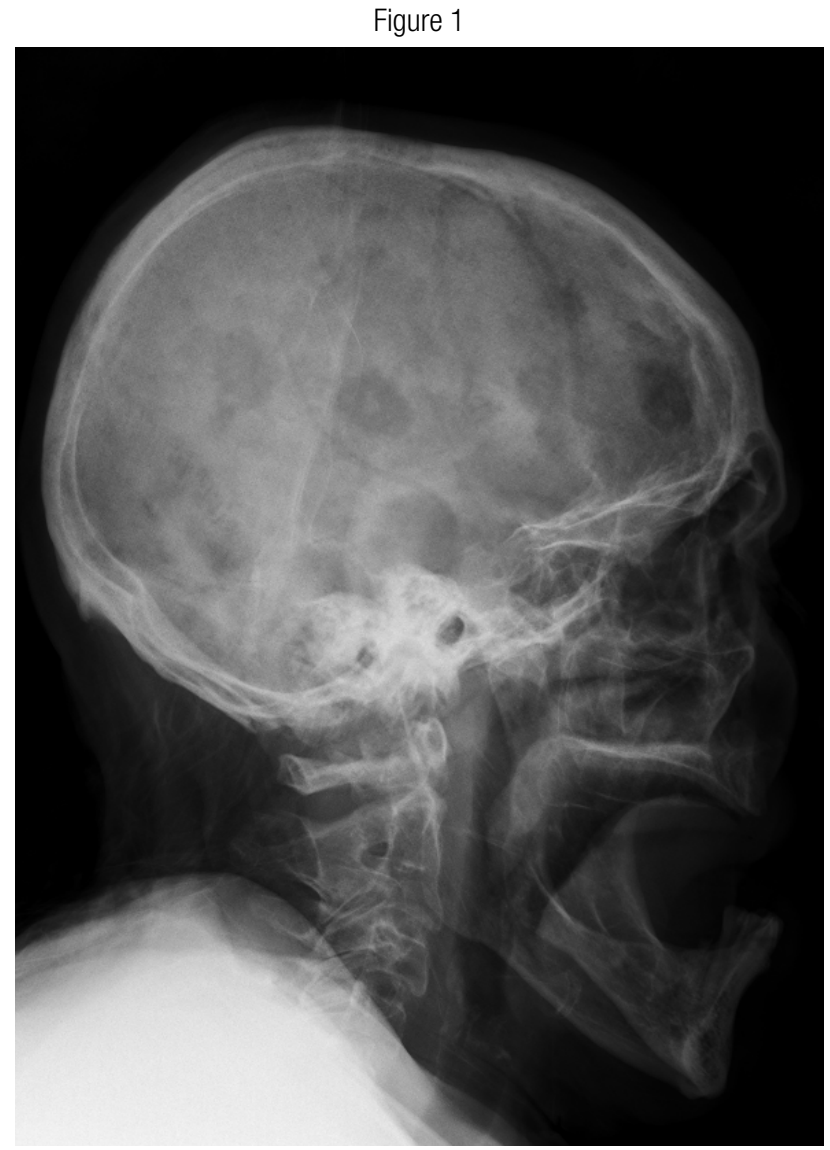

Figure 1 